\title{
Adsorption of Aniline from Aqueous System by Highly Fluorinated Polymers of Intrinsic Microporosity (PIM-2)
}

\section{Bekir SATILMIŞ ${ }^{1 *}$}

\begin{abstract}
Polymers of Intrinsic Microporosity (PIMs) are documented as suitable materials for organic adsorption applications. Intrinsic porous structure along with a solution-processability behaviour make them attractive for the adsorption of organic contaminants from water. In this research, PIM-2 powder was synthesised and the exploitation of PIM-2 for aniline removal was studied using a batch adsorption process. The effect of several variables were explored including initial aniline concentration, adsorption time and temperature. Adsorption reached the equilibrium after five hours and experimental adsorption capacity ( $q_{\mathrm{e}, \text { exp }}$ ) was found as $79.7 \mathrm{mg} \mathrm{g}^{-1}$ for aniline at $\mathrm{pH} 6$ and 298K. Isotherm (Langmuir, Freundlich and Liu) and kinetic models (pseudo first order and pseudo second order) and elovich model were applied using non-linear regression analysis. In addition, various errors analysis approaches were used to determine the most appropriate isotherm and kinetic models. Pseudo second order model and Liu isotherm fitted well for aniline adsorption. Maximum adsorption capacity $\left(q_{\mathrm{m}}\right)$ were computed as $82.4 \mathrm{mg} \mathrm{g}^{-1}$ for aniline at $\mathrm{pH} 6$ and $298 \mathrm{~K}$ based on the Liu adsorption model. Thermodynamic studies revealed that the adsorption process was physical, spontaneous and exothermic.
\end{abstract}

Keywords: Polymers of Intrinsic Microporosity (PIM-2), aniline, adsorption, kinetic, isotherm, thermodynamic.

${ }^{1}$ Bekir SATILMIŞ (Orcid ID: 0000-0002-3704-8628), Kirsehir Ahi Evran University, Vocational School of Health Services, Department of Medical Services and Techniques, Kirsehir, Turkey

*Corresponding Author: Bekir SATILMIŞ, e-mail: bekir.satilmis@ahievran.edu.tr

Geliş tarihi / Received: 22-04-2020

Kabul tarihi / Accepted: 18-06-2020 


\section{INTRODUCTION}

Aniline is a broadly employed organic precursor for producing polymeric materials, pharmaceuticals, rubber accelerators, pigments, and dyes (Rahdar et al., 2020; Yi et al., 2020). It is an extremely toxic compound that can cause serious damage on human body as it can react with the blood and convert haemoglobin into methaemoglobin. Long-term exposure to aniline may cause a blood disorder for the human body (Midda et al., 2018). It also poses a threat to the aquatic environment since it is a persistent chemical with bio-accumulative potential (Zeng and Huang, 2020). In recent years, aniline demand has increased in parallel with the industrial developments. Increased usage of aniline has also raised its emission into the aquatic environment (Gao et al., 2015). Thus, the removal of aniline from water has a practical significance. Various removal methods have been proposed including adsorption (An et al., 2010), biodegradation (Gheewala and Annachhatre, 1997) and oxidation (Sriprom et al., 2014). Adsorption by porous materials is a commonly used method due to the simplicity and efficiency against other methods.

Polymers of intrinsic microporosity (PIMs) are novel polymeric compounds which display excellent properties due to their rigid and contorted assemblies (Budd et al., 2004). They exhibit high surface area and high free volume (Budd et al., 2005; McKeown et al., 2005). They also show solutionprocessability which makes them distinguishable against other porous materials since most of the porous adsorbents are insoluble. A number of PIM polymers have been synthesised but PIM-1 has gained the main attention as it can be synthesised using commercially available monomers. It can also be generated in different forms owing to the high molecular weight (Budd et al., 2008). Recently, PIM-1 has been used for aniline removal from air and water in the form of fiber, powder and film (Satilmis and Uyar, 2018). The study shows that powder and fiber adsorption capacities and kinetics are quite close to each other while the film form shows slower adsorption. Additionally, handling simplicity makes the fiber more practical for real-time applications. Recently, we have synthesised high surface area PIM-2 polymer using commercially available monomers; Decafluorobiphenyl (DFBP) and 5,5',6,6'Tetrahydroxy-3,3,3',3'-tetramethyl-1,1'-spirobisindane (TTSBI) by improving the previous synthesis method (Sato et al., 2018; Satilmis and Uyar, 2019). PIM-2 is soluble in common laboratory solvents such as tetrahydrofuran, chloroform and tetrachloroethane. Hence, we have presented the successful production of electrospun PIM-2 fibers (Satilmis and Uyar, 2019) and PIM-2 dense membranes (Fuoco et al., 2020). Since the membrane production of PIM-2 was not possible until recently, its adsorptive properties have not been examined in detailed yet.

Therefore, in the present research, we synthesised PIM-2 polymer and subsequently the aniline adsorption performance of PIM-2 from water was explored. To our knowledge, no one has studied the aniline removal efficiency of PIM-2 from water. As we predicted, PIM-2 can effectively remove aniline from an aqueous system. Ability to produce PIM-2 in dense and fibrous membrane forms may enable its practical use in various separation applications. Furthermore, the effect of operating conditions on the adsorption process was studied prior to determining adsorption isotherms, kinetic models and thermodynamic constants.

\section{MATERIALS AND METHODS}

\section{Materials}

5,5',6,6'-Tetrahydroxy-3,3,3',3'-tetramethyl-1,1'-spirobisindane (98\%, TTSBI) and potassium carbonate $\left(99.0 \%\right.$, anhydrous, $\mathrm{K}_{2} \mathrm{CO}_{3}$ ) were purchased from Alfa Aeser. TTSBI was recrystallized based on the reported procedure (Satilmis and Uyar, 2019). Decafluorobiphenyl (99\%, DFBP), methanol 
( $\geq 99.9 \%, \mathrm{MeOH})$, aniline (99\%) and dimethylformamide (99.8\%, DMF), were received from Sigma Aldrich and used as purchased.

\section{Synthesis and characterization of PIM-2}

Synthesis and characterization of PIM-2 polymer was carried out as described in our previous study (Satilmis and Uyar, 2019). Briefly, TTSBI, $\mathrm{K}_{2} \mathrm{CO}_{3}$, and anhydrous DMF were mixed in a flask under argon atmosphere. Then, complete dissolution was achieved by heating the mixture to $100{ }^{\circ} \mathrm{C}$. Meanwhile, DFBP was dissolved in anhydrous DMF and this solution was injected into the reaction mixture. The reaction was executed at $100{ }^{\circ} \mathrm{C}$ for $48 \mathrm{~h}$ and the product was treated with an aqueous $\mathrm{HCl}$ $(5 \% \mathrm{v} / \mathrm{v})$ before drying at $150{ }^{\circ} \mathrm{C}$ for overnight.

\section{Methods}

FT-IR spectrum was recoded on a Bruker Vertex 70 FT-IR spectrometer. ${ }^{1} \mathrm{H}$ NMR spectrum was compiled using a Bruker (DPX-400 MHz) NMR spectrometer in $\mathrm{CDCl}_{3}$. Thermal changes of PIM-2 powder were investigated using TA Q500 thermogravimetric analyser under nitrogen atmosphere. Quantitative determination of aniline was accomplished by Genesis10s UV-Vis spectrometer.

\section{Sorption studies}

Aniline stock (500 $\mathrm{mg} \mathrm{L}^{-1}$ ) was prepared in deionized water. Genesis $10 \mathrm{~s}$ UV-Vis spectrometer was used to record the absorbance values of calibration solutions at $280 \mathrm{~nm}$ ( $\left.\lambda_{\max }\right)$. Adsorption experiments were conducted in $20 \mathrm{~mL}$ aniline solutions in the concentration ranging from 50 to $500 \mathrm{mg}$ $\mathrm{L}^{-1}$ using a batch process. $10 \mathrm{mg}$ PIM-2 powder was placed in aniline solutions and stirred for $5 \mathrm{~h} .100$ $\mu \mathrm{L}$ solution was taken and diluted by water. Adsorbed aniline, $q_{\mathrm{e}}\left(\mathrm{mg} \mathrm{g}^{-1}\right)$, was calculated using equation 1.

$$
q_{e}=\frac{\left(C_{0}-C_{e}\right) \times V}{w}
$$

where, $C_{0}\left(\mathrm{mg} \mathrm{L}^{-1}\right)$, and $C_{\mathrm{e}}\left(\mathrm{mg} \mathrm{L}^{-1}\right)$ exhibits the solution concentrations at the initial and at the equilibrium, respectively. $\mathrm{V}(\mathrm{L})$ is the volume of aniline solution and $\mathrm{w}(\mathrm{g})$ represents the amount of PIM-2. All adsorption experiments were conducted as triplicates and mean values were used.

The effect of contact time was studied using 50 and $500 \mathrm{mg} \mathrm{L}^{-1}$ aniline solution for $5 \mathrm{~h}$. The impact of initial concentration was investigated in the range of 50 to $500 \mathrm{mg} \mathrm{L}^{-1}$. The effect of temperature was explored using the solution temperatures of $283,298,313 \mathrm{~K}$ at natural $\mathrm{pH}$.

Non-linear regression analysis method was applied to calculate the constants of isotherms and kinetic models. Microsoft Excel (Solver add-in) was operated to predict the data. As stated recently (Lima et al., 2019), the non-linear method is indispensable for obtaining correct parameters, particularly for thermodynamic parameters. Experimental and calculated equilibrium data was also compared by means of the correlation coefficient $\left(\mathrm{R}^{2}\right)$, chi-square test $\left(\chi^{2}\right)$ and the relative error $(\Delta \mathrm{q})$ methods as displayed in Equation 2-5 (Günay et al., 2007; Foo and Hameed, 2010).

$$
\begin{gathered}
S S E=\sum_{i=1}^{n}\left(q_{e, c a l}-q_{e, e x p}\right)_{i}^{2} \\
R^{2}=\frac{\left(q_{e, e x p}-\bar{q}_{e, c a l}\right)^{2}}{\sum\left(q_{e, \exp }-\bar{q}_{e, c a l}\right)^{2}+\left(q_{e, \exp }-q_{e, c a l}\right)^{2}}
\end{gathered}
$$




$$
\begin{gathered}
\chi^{2}=\sum_{i=1}^{n} \frac{\left(q_{e, c a l}-q_{e, \exp }\right)^{2}}{q_{e, \exp }} \\
\Delta q(\%)=\sqrt{\sum \frac{\left[\left(q_{e, e x p}-q_{e, c a l}\right) / q_{e, \text { exp }}\right]^{2}}{N-1}} \times 100
\end{gathered}
$$

where $\left(q_{\mathrm{e}, \text { exp }}\right),\left(q_{\mathrm{e}, \mathrm{cal}}\right)$ and ( $\left.\bar{q}_{\mathrm{e}, \mathrm{cal}}\right)$ represent experimental, calculated and the mean value of calculated equilibrium capacities, respectively. The number of measurements was denoted by $\mathrm{N}$.

\section{RESULTS AND DISCUSSION}

\section{Characterization of PIM-2}

Polymers of intrinsic microporosity (PIMs) have attained adequate consideration owing to their high surface area and high free volume. Although the first-generation PIM polymers (PIM-(1-6)) have been reported in 2004, the reported procedure only enables the production of PIM-1 with a high molecular weight. PIM-1 could be produced using commercially available monomers and it is soluble in common laboratory solvents such as chloroform and tetrahydrofuran. A combination of high molecular weight and solution-processability enable the production of PIM-1 in different forms including powder (Budd et al., 2008), fiber (Satilmis and Uyar, 2018) and film forms (Budd et al., 2008). Hence, various application opportunities are possible for PIM-1 including adsorption, catalysis, gas separation and sensor (McKeown and Budd, 2006). Although PIM-2 shows similar properties with PIM1 such as synthesis from commercial monomers (Figure 1a), solubility in common organic solvents, high surface area $\left(600 \mathrm{~m}^{2} \mathrm{~g}^{-1}\right)$ and high free volume, the production of PIM-2 with a high molecular weight was managed only recently (Satilmis and Uyar, 2019). Therefore, the adsorptive properties of PIM-2 have not been investigated in detail yet. For this reason, we have first synthesised and characterized PIM-2 based on the reported procedure (Satilmis and Uyar, 2019). The purity of PIM-2 was confirmed using FT-IR and ${ }^{1} \mathrm{H}$ NMR spectroscopies and TGA technique.

(a)

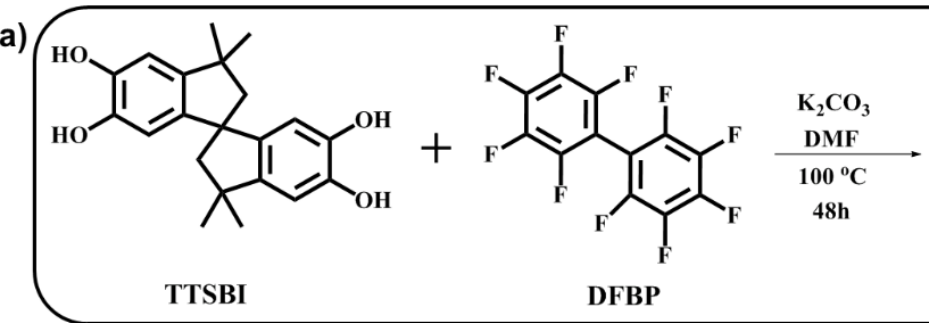

(b)

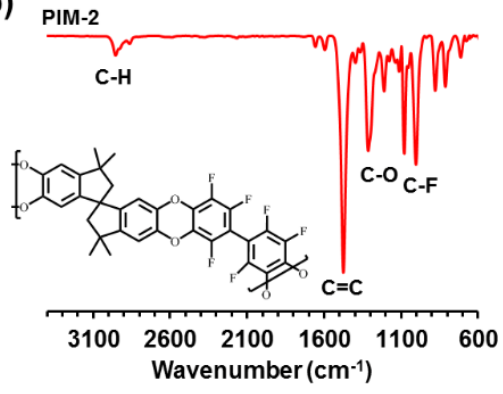

(c)

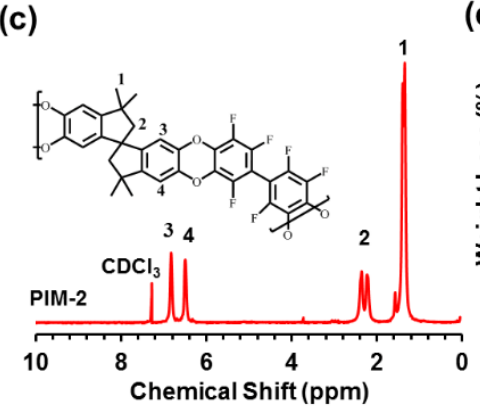

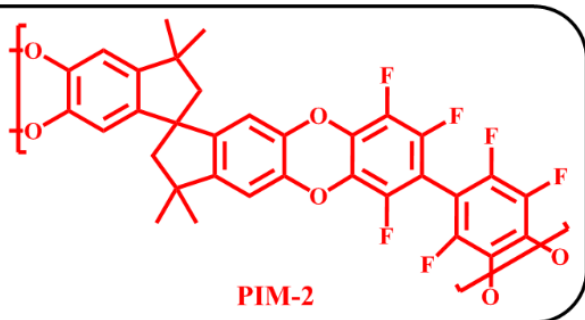

(d)

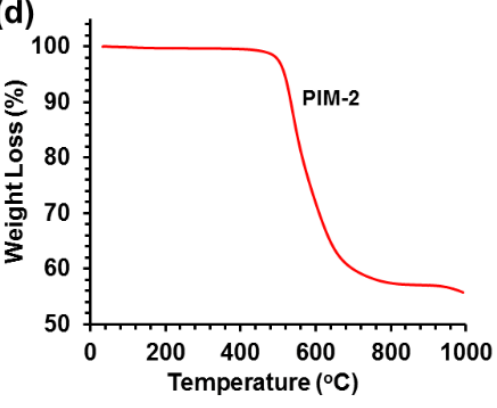

Figure 1. (a) Synthesis path of PIM-2, (b) FT-IR and (c) ${ }^{1}$ H NMR spectra and (d) TGA of PIM-2

FT-IR spectrum of PIM-2 is presented in Figure $1 \mathrm{~b}$ showing aliphatic C-H peaks $\left(\sim 3000 \mathrm{~cm}^{-1}\right)$, aromatic C-C stretches $\left(1491 \mathrm{~cm}^{-1}\right), \mathrm{C}-\mathrm{O}\left(1299 \mathrm{~cm}^{-1}\right)$ and C-F $\left(1076\right.$ and $\left.995 \mathrm{~cm}^{-1}\right)$ vibrations (Sato et 
al., 2018). ${ }^{1} \mathrm{H}$ NMR spectrum of PIM-2 is displayed in Figure 1c exhibiting characteristic PIM peaks arise from TTSBI units which are aliphatic protons (1.0 to $2.5 \mathrm{ppm}$ : $\mathrm{H} 1$ and $\mathrm{H} 2$ ) and aromatic protons (6.1-7.0 ppm: H3, H4) (Sato et al., 2018; Satilmis and Uyar, 2019). Moreover, thermal behaviour of PIM-2 was studied using TGA to ensure no residuals remain in the polymer. As displayed in Figure 1d, PIM-2 shows no weight loss before $500{ }^{\circ} \mathrm{C}$ after which backbone degradation occurs (Satilmis and Uyar, 2019). Following that we have examined the affinity of PIM-2 against aniline in a batch adsorption process.

\section{Effect of contact time}

The relationship between the contact time and aniline uptake onto PIM-2 is demonstrated in Figure 2a using two different initial aniline concentrations (50 and $\left.500 \mathrm{mg} \mathrm{L}^{-1}\right)$. It is apparent that the adsorbed amount increased instantly with the time. Approximately $56 \%$ of adsorption occurred at the first $30 \mathrm{~min}$ and the equilibrium was accomplished within $300 \mathrm{~min}$ after which the adsorption remained almost constant. This behaviour could be interpreted by the vacancy of the active sites on the PIM-2. Initially, active sites were unoccupied and the availability was reduced by the time (Harrache et al., 2019; Igberase et al., 2019).
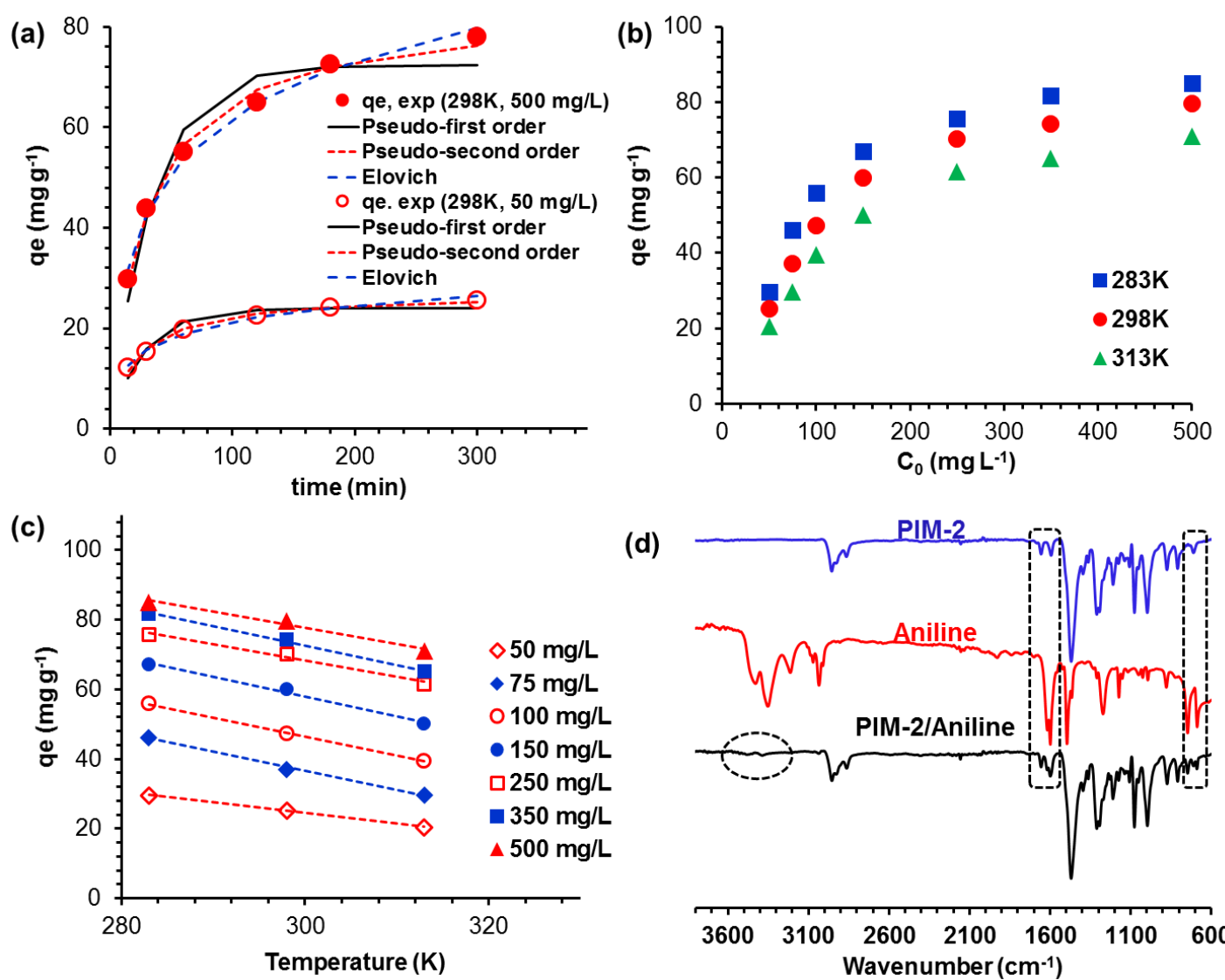

(d)

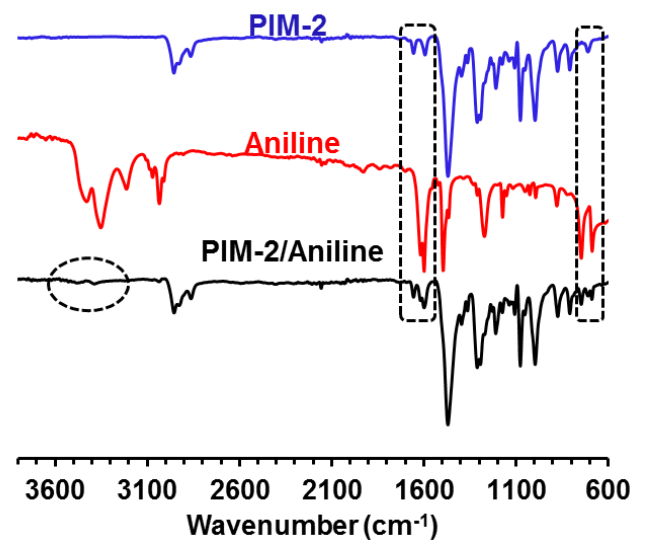

Figure 2. (a) Effect of contact time and applied kinetic models, (b) effect of initial aniline concentration and (c) effect of temperature on the adsorption of aniline onto PIM-2. (d) FT-IR spectra of PIM-2, aniline and PIM-2 after in contact with aniline.

\section{Effect of initial concentration}

Figure $2 \mathrm{~b}$ illustrates the relationship between initial aniline concentrations and equilibrium adsorption capacity of PIM-2 at three different temperatures. As displayed in Figure $2 b$, increasing the 
initial concentration causes a marked increase in the adsorption. When it was elevated from 50 to 500 $\mathrm{mg} \mathrm{L}^{-1}$, the maximum uptake was raised from 25.2 to $79.7 \mathrm{mg} \mathrm{g}^{-1}$ at $298 \mathrm{~K}$. Similar trends were also observed at 283 and $313 \mathrm{~K}$ temperatures.

\section{Impact of temperature}

The effect of temperature on the adsorption was assessed at 283, 298 and $313 \mathrm{~K}$. Adsorption capacities reduced with increased temperature at various concentrations, as depicted in Figure $2 \mathrm{c}$. The equilibrium capacity reduced from 85.1 to $71 \mathrm{mg} \mathrm{g}^{-1}$ at $500 \mathrm{mg} \mathrm{L}^{-1}$ aniline concentration when the solution temperature was elevated from 283 to $313 \mathrm{~K}$. This indicates that low temperature favors the aniline removal by PIM-2 and is exothermic in nature.

\section{Adsorption kinetics}

The adsorption kinetic is a vital parameter for choosing optimum operating conditions. Figure 2a exhibits the relationship between equilibrium adsorption $\left(q_{\mathrm{e}}\right)$ capacity and contact time. Finding the variables by linear regression method brings some drawbacks as it presumes that the scatter around the line obeys Gaussian distribution. On the other hand, using a non-linear regression method provides more reliable data but it also requires a more complex mathematical approach. Therefore, in the present study, three non-linear kinetic models were employed; pseudo-first-order (PFO) (Lagergren, 1898), pseudosecond-order (PSO) (Ho and McKay, 1999), and Elovich equation (McLintock, 1967) models. Applied equations for the stated models are presented in Table 1.

The interaction between adsorbent (PIM-2) and adsorbate (aniline) could be deduced from the best fitting kinetic model. When one aniline molecule interacts with one active site of PIM-2, this is usually described by PFO model (Liu et al., 2017; Khan et al., 2018). On the other hand, if it interacts with two active sites of PIM-2, it usually follows the PSO model. Elovich equation is mostly valid for heterogeneous surfaces and is used to describe chemisorption kinetic (McLintock, 1967). Calculated kinetic parameters and their error analysis data are demonstrated in Table 1. It has been stated that the comparison of kinetic data by a single analysis method may cause misinterpretation of the data (Lima et al., 2015). Thus, using a combination of these analysis methods is necessary to detect the best model. In general, the highest value of $\mathrm{R}^{2}$ and the lowest values of SSE, $\chi^{2}$ and $\Delta \mathrm{q}$ would reveal the best model. In the beginning, the adsorpion kinetic was studied using $500 \mathrm{mg} \mathrm{L}^{-1}$ initial aniline concentration to distinguish the best kinetic model. However, PSO model and Elovich model could not be distinguished within the precision of data presented in Figure 2a. As displayed in Table 1, while the highest value of $\mathrm{R}^{2}$ and the lowest value of $\Delta \mathrm{q}$ are obtained in the PSO model, Elovich model shows the lowest values of SSE and $\chi^{2}$. A possible reason for this inconsistency was thought to be originated from diluting problems. Therefore, we have performed the same experiments with $50 \mathrm{mg} \mathrm{L}^{-1}$ initial aniline concentrations to reduce the error from the experiment. However, the precision of the data was still insufficient to distinguish between the two models. Since we are aiming to measure small concentration differences in a short time, the solubility or the volatility of the aniline in water may affect the UV results. Consequently, we used FT-IR spectroscopy to understand whether the interaction between PIM-2 and aniline is physical or chemical. In the case of chemical interactions (chemisorption), new vibrations should be observed in aniline adsorbed PIM-2 spectrum. Figure 2d shows the FT-IR spectra of PIM-2, aniline and PIM-2 after in-contact with aniline samples. As can be seen, no new vibrations or shifts can be distinguished from the spectra, which suggests that the interaction between PIM-2 and aniline is physical. Thus, we have concluded that the PSO model is more suitable for defining the adsorption process. 
Table 1. Kinetic equations and obtained data for aniline adsorption onto PIM-2 using 50 and $500 \mathrm{mg} \mathrm{L}^{-1}$ initial aniline solutions.

\begin{tabular}{|c|c|c|c|c|}
\hline Kinetic model & Equation* $^{*}$ & Parameter & Aniline (500 $\left.\mathrm{mg} \mathrm{L}^{-1}\right)$ & Aniline (50 $\left.\mathrm{mg} \mathrm{L}^{-1}\right)$ \\
\hline & & $q_{\mathrm{e},} \exp .\left(\mathrm{mg} \mathrm{g}^{-1}\right)$ & 78.0 & 25.6 \\
\hline \multirow{6}{*}{$\begin{array}{l}\text { Pseudo First } \\
\text { Order Model }\end{array}$} & \multirow{6}{*}{$q_{t}=q_{e, c a l}\left(1-\exp \left(-k_{1} t\right)\right.$} & $\mathrm{k}_{1}\left(\min ^{-1}\right)$ & 0.029 & 0.037 \\
\hline & & $q_{\text {e-model }}\left(\mathrm{mg} \mathrm{g}^{-1}\right)$ & 72.5 & 24.0 \\
\hline & & SSE & 101.3 & 10.9 \\
\hline & & $\mathrm{R}^{2}$ & 0.943 & 0.927 \\
\hline & & $\chi^{2}$ & 1.91 & 0.65 \\
\hline & & $\Delta q(\%)$ & 9.1 & 9.3 \\
\hline \multirow{6}{*}{$\begin{array}{l}\text { Pseudo Second } \\
\text { Order Model }\end{array}$} & \multirow{6}{*}{$q_{t}=\frac{q_{e, c a l}^{2} k_{2} t}{1+q_{e, c a l} k_{2} t}$} & $\mathrm{k}_{2}\left(\mathrm{~g} \mathrm{mg}^{-1} \mathrm{~min}^{-1}\right)$ & 0.0004 & 0.0018 \\
\hline & & $q_{\mathrm{e}-\mathrm{model}}\left(\mathrm{mg} \mathrm{g}^{-1}\right)$ & 83.5 & 26.9 \\
\hline & & SSE & 13.9 & 1.0 \\
\hline & & $\mathrm{R}^{2}$ & 0.999 & 0.999 \\
\hline & & $\chi^{2}$ & 0.24 & 0.10 \\
\hline & & $\Delta \mathrm{q}(\%)$ & 3.0 & 3.8 \\
\hline \multirow{6}{*}{ Elovich } & \multirow{6}{*}{$q_{t}=\frac{1}{b} \ln a b+\frac{1}{b} \ln t$} & $\beta\left(\mathrm{g} \mathrm{mg}^{-1}\right)$ & 0.062 & 0.216 \\
\hline & & $\mathrm{a}\left(\mathrm{mg} \mathrm{g}^{-1} \min ^{-1}\right)$ & 7.61 & 4.61 \\
\hline & & SSE & 10.2 & 1.9 \\
\hline & & $\mathrm{R}^{2}$ & 0.994 & 0.986 \\
\hline & & $\chi^{2}$ & 0.22 & 0.09 \\
\hline & & $\Delta q(\%)$ & 3.3 & 3.1 \\
\hline
\end{tabular}

*: $\mathrm{q}_{\mathrm{e} \text {, cal }}$ represents calculated adsorption capacity. The uptake at time $\mathrm{t}$ is denoted by $\mathrm{qt} . \mathrm{k}_{1}, \mathrm{k}_{2}$, and $\mathrm{k}_{\mathrm{i}}$ are the rate constants. $\alpha$ and $\mathrm{b}$ are the rate constants of the Elovich model

\section{Adsorption isotherms}

Aniline adsorption onto PIM-2 was determined as a function of aniline concentration at the equilibrium (Figure 3) to explain the adsorption process (Ahmadi et al., 2019). Data was analyzed by three isotherm models (Langmuir (Langmuir, 1916), Freundlich (Freundlich, 1906), and Liu (Liu et al., 2003)) using the non-linear approach. The non-linear equations, values of estimated isotherm constants and their statistical parameters are represented in Table 2 for respective isotherm models. Figure 3 displays the experimental and calculated aniline uptakes by PIM-2 for three different temperatures; $283 \mathrm{~K}, 298 \mathrm{~K}$ and $313 \mathrm{~K}$.
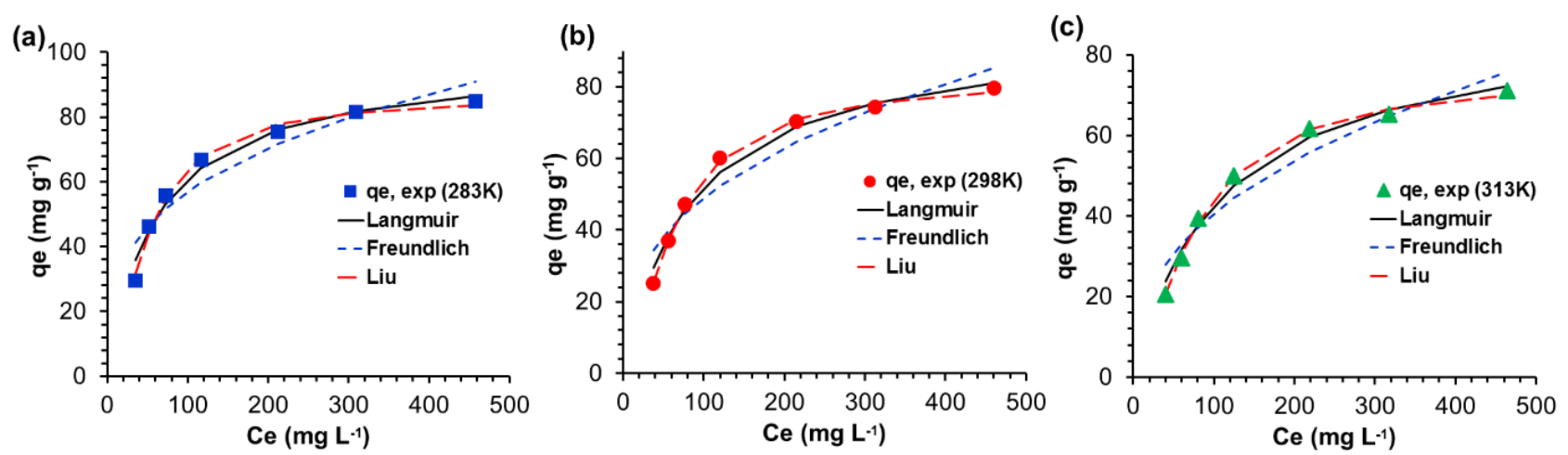

Figure 3. Comparison of adsorption isotherms for aniline adsorption on PIM-2 at (a) $283 \mathrm{~K}$, (b) $298 \mathrm{~K}$ and (c) $313 \mathrm{~K}$ 
Table 2. Isotherm equations and obtained data for aniline adsorption onto PIM-2

\begin{tabular}{|c|c|c|c|c|c|}
\hline \multirow{3}{*}{ Isotherm } & \multirow{3}{*}{ Equation* } & \multirow{3}{*}{ Parameters } & \multicolumn{3}{|c|}{ Aniline } \\
\hline & & & \multicolumn{3}{|c|}{ Temperature (K) } \\
\hline & & & 283 & 298 & 313 \\
\hline \multirow{8}{*}{ Langmuir } & \multirow{8}{*}{$q_{e}=\frac{q_{m} K_{L} C_{e}}{1+K_{L} C_{e}}$} & $q_{\mathrm{m}}\left(\mathrm{mg} \mathrm{g}^{-1}\right)$ & 98.1 & 96.0 & 89.3 \\
\hline & & $\mathrm{K}_{\mathrm{L}}\left(\mathrm{L} \mathrm{mg}^{-1}\right)$ & 0.016 & 0.012 & 0.009 \\
\hline & & $\mathrm{R}_{1}$ & 0.11 & 0.14 & 0.18 \\
\hline & & $\mathrm{K}_{\mathrm{L}}$ & 0.55 & 0.63 & 0.69 \\
\hline & & SSE & 57.92 & 42.22 & 31.18 \\
\hline & & $\mathrm{R}^{2}$ & 0.977 & 0.983 & 0.986 \\
\hline & & $\chi^{2}$ & 1.606 & 1.136 & 0.971 \\
\hline & & $\Delta q(\%)$ & 9.00 & 7.76 & 7.78 \\
\hline \multirow{6}{*}{ Freundlich } & \multirow{6}{*}{$q_{e}=K_{F} C_{e}^{1 / n}$} & $1 / \mathrm{n}$ & 0.31 & 0.36 & 0.41 \\
\hline & & $\mathrm{K}_{\mathrm{F}}\left(\mathrm{L} \mathrm{g}^{-1}\right)$ & 13.78 & 9.30 & 6.23 \\
\hline & & SSE & 260.78 & 219.46 & 159.09 \\
\hline & & $\mathrm{R}^{2}$ & 0.904 & 0.919 & 0.932 \\
\hline & & $\chi^{2}$ & 6.38 & 5.55 & 4.68 \\
\hline & & $\Delta q(\%)$ & 17.40 & 16.88 & 16.97 \\
\hline \multirow{7}{*}{ Liu } & \multirow{7}{*}{$q_{e}=\frac{q_{m}\left(K_{L i u} C_{e}\right)^{n} \text { Liu }}{1+\left(K_{L i u} C_{e}\right)^{n_{L i u}}}$} & $q_{m}\left(\mathrm{mg} \mathrm{g}^{-1}\right)$ & 86.36 & 82.36 & 75.19 \\
\hline & & $\mathrm{K}_{\mathrm{Liu}}\left(\mathrm{L} \mathrm{mg}^{-1}\right)$ & 0.020 & 0.016 & 0.013 \\
\hline & & $\mathrm{n}_{\text {Liu }}$ & 1.54 & 1.51 & 1.46 \\
\hline & & SSE & 16.92 & 4.58 & 5.19 \\
\hline & & $\mathrm{R}^{2}$ & 0.993 & 0.998 & 0.998 \\
\hline & & $\chi^{2}$ & 0.342 & 0.067 & 0.106 \\
\hline & & $\Delta q(\%)$ & 3.67 & 1.33 & 2.01 \\
\hline
\end{tabular}

*: $\mathrm{q}_{\mathrm{m}}$ is the equilibrium uptake, $\mathrm{C}_{\mathrm{e}}\left(\mathrm{mg} \mathrm{L}^{-1}\right)$ is the aniline concentration at the equilibrium. $\mathrm{K}_{\mathrm{L}}, \mathrm{K}_{\mathrm{F}}, \mathrm{K}_{\mathrm{Liu}}$ are the constants. $\mathrm{n}_{\text {Liu }}$ is the model exponent of Liu isotherm. $1 / \mathrm{n}$ is the adsorption intensity

Regarding isotherm models, Langmuir and Freundlich are the most used two-parameter isotherm models. Langmuir isotherm proposes that the adsorption happens merely a single layer on the homogenous adsorbent surface. Hence, following the monolayer formation no further adsorption takes place. Freundlich isotherm suggests the heterogeneity of the adsorbent surface (Foo and Hameed, 2010). Additionally, Liu isotherm is a three-parameter isotherm model which incorporates Langmuir and Freundlich models (Liu et al., 2003; Lima et al., 2015). Thus, the infinite adsorption by Freundlich and the monolayer adsorption by Langmuir are discarded by Liu model. Besides, Liu model does not have any limitation considering the exponent value $\left(\mathrm{n}_{\mathrm{Liu}}\right)$, which can be any positive value unlike other threeparameter isotherm models such Sips and Redlich-Peterson isotherms exponents (Lima et al., 2015). Therefore, these three isotherm models were selected to investigate the most appropriate model for aniline adsorption onto PIM-2. Considering the isotherm models, Liu isotherm model have the greatest correlation coefficients $\left(\mathrm{R}^{2}\right)$ and the lower statistical errors compared to Langmuir and Freundlich models. The experimental and calculated values show the best correlation in Liu model, which indicates the coexistence of heterogenous and monolayer surface conditions. Table 2 shows the calculated $q_{\mathrm{m}}$ values and isotherm parameters for aniline adsorption at different temperatures. 


\section{Adsorption thermodynamics}

Studying adsorption in different temperatures provides valuable information about thermodynamic parameters (Gibbs free energy; $\Delta \mathrm{G}^{\mathrm{o}}$, enthalpy change; $\Delta \mathrm{H}^{\mathrm{o}}$, and entropy change; $\Delta \mathrm{S}^{\circ}$ ) and, thus, the practicality of the adsorption process. The estimation of these parameters is usually achieved using the Van't Hoff equation (Equation 6) (Ghosal and Gupta, 2017; Lima et al., 2019). Thus, the basic requirement for obtaining correct thermodynamic parameters is to use correct equilibrium constant values $(\mathrm{K})$.

$$
\Delta G^{o}=-R T \ln K
$$

where $\mathrm{R}$ indicates the gas constant, $\mathrm{T}$ shows temperature $(\mathrm{K})$ and $\mathrm{K}$ represents thermodynamic equilibrium constant.

Equation 6 can be combined with Equation 7 by considering the $3^{\text {rd }}$ principle of the thermodynamics to derive Equation. 8 .

$$
\begin{aligned}
& \Delta G^{o}=\Delta H^{o}-T \Delta S^{o} \\
& \ln K=-\frac{\Delta H^{o}}{R T}+\frac{\Delta S^{o}}{R}
\end{aligned}
$$

Ultimately, enthalpy $\left(\Delta \mathrm{H}^{\circ}\right)$ and entropy $\left(\Delta \mathrm{S}^{\circ}\right)$ values could be deduced from the plot of $\ln \mathrm{K}$ versus $1 / \mathrm{T}$. Adsorption literature provides various ways to obtain equilibrium constants. However, as reported recently (Lima et al., 2019), most of these methods may generate incorrect equilibrium constants. Lima et al. (Lima et al., 2019) have demonstrated that correct equilibrium constant could only be attained by acquiring adsorption isotherms at various temperatures and then generating their non-linear fittings. Then, the dimensionless equilibrium constant could be derived from the equilibrium constant of the best fitted isotherm (Equation 9).

$$
K=\frac{K_{L} \times 1000 \times \text { molecular weight of adsorbate }}{\gamma}
$$

According to isotherm data, Liu isotherm gave the best fit for the adsorption of aniline onto PIM2. Hence, equilibrium constants $(\mathrm{K})$ were derived from Liu constants $\left(\mathrm{K}_{\mathrm{Liu}}\right)$. Plots of $\ln \mathrm{K}$ against $1 / \mathrm{T}$ (Figure 4) provides $\Delta \mathrm{H}^{\circ}$ and $\Delta \mathrm{S}^{\circ}$ values (Table 3) based on the Equation 8 . The negative value of $\Delta \mathrm{H}^{\circ}$ $\left(-10.8 \mathrm{~kJ} \mathrm{~mol}^{-1}\right)$ reveals that the adsorption is an exothermic process. The positive value of $\Delta \mathrm{S}^{\circ}(24.4 \mathrm{~J}$ $\mathrm{K}^{-1} \mathrm{~mol}^{-1}$ ) denotes an improved randomness at the solid/solution interface. Additionally, $\Delta \mathrm{G}^{\mathrm{o}}$ values were in the range of -17.7 to $-18.4 \mathrm{~kJ} \mathrm{~mol}^{-1}$ showing the adsorption of aniline onto PIM-2 is spontaneous and physical as the free energy change is lower than $40 \mathrm{~kJ} \mathrm{~mol}^{-1}$ (Satilmis, 2020).

Consequently, the present study showed that PIM-2 exhibits similar adsorption properties with PIM-1 polymer which showed high aniline uptake reported recently (161.2 $\mathrm{mg} \mathrm{g}^{-1}$ ) (Satilmis and Uyar, 2018). The previous study with PIM-1 was mainly focussed on the adsorption capacity rather than the kinetic and thermodynamic studies. Regarding the equilibrium time, both polymers can reach the maximum aniline uptake within the 5h. Although PIM-2 capacity is lower than that of PIM-1, it displays greater adsorption capacity than many other adsorbents. Indeed, Table 4 displays the most promising polymer-based materials/resins and their maximum adsorption capacities for the removal of aniline. As can be seen, the adsorption capacity $\left(q_{\mathrm{m}}\right)$ of these polymers can reach up to $1059 \mathrm{mg} \mathrm{g}^{-1}$ (AZO-POP-1) (Zhou et al., 2018). However, all these polymeric adsorbents are produced by crosslinking which makes resulting material insoluble and unprocessable. Thus, they can only be used in the powder form. One of 
the most remarkable features of PIMs is that they could be produced in the fiber form which provides a significant advantage over other insoluble adsorbents in practical applications (Satilmis and Uyar, 2019). PIM-1 and PIM-2 could be used as promising supports for these high-performance materials for further application purposes. Moreover, PIM-2 could be considered even better material than PIM-1 since the fiber production by electrospinning can be scaled up easily with respect to PIM-1 (Satilmis and Uyar, 2019).

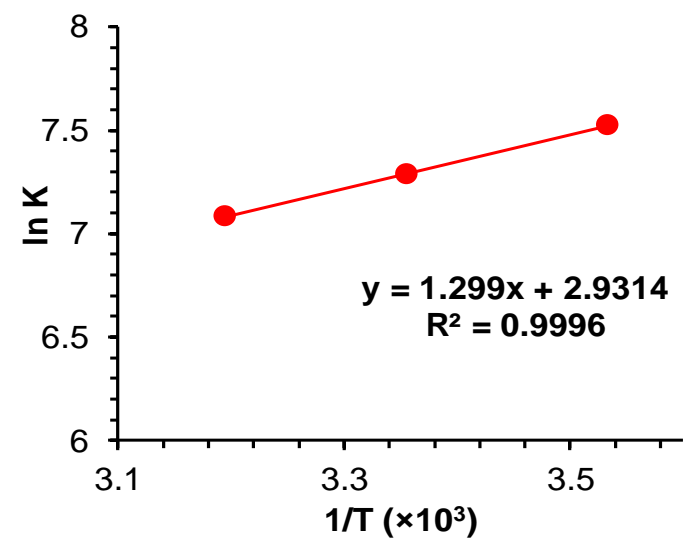

Figure 4. Plot of $\ln \mathrm{K}$ versus 1/T for aniline adsorption on PIM-2

Table 3. Calculated values of $\mathrm{K}$ and thermodynamic parameters.

\begin{tabular}{ccccc}
\hline \multirow{3}{*}{ Isotherm } & Parameters & \multicolumn{3}{c}{ Aniline } \\
\cline { 3 - 5 } & & $\mathbf{2 8 3}$ & $\mathbf{2 0 m p e r a t u r e ~ ( K ) ~}$ & $\mathbf{3 1 3}$ \\
\hline \multirow{3}{*}{ Liu } & $\ln \mathrm{K}$ & 7.52 & 7.29 & 7.08 \\
& $\Delta \mathrm{H}\left(\mathrm{kJ} \mathrm{mol}^{-1}\right)$ & & -10.8 & \\
& $\Delta \mathrm{S}\left(\mathrm{J} \mathrm{K}^{-1} \mathrm{~mol}^{-1}\right)$ & -17.70 & -18.06 & -18.43 \\
\hline
\end{tabular}

Table 4. Comparison of polymer-based adsorbents for aniline removal.

\begin{tabular}{|c|c|c|c|c|}
\hline \multirow[t]{2}{*}{ Adsorbent } & \multicolumn{2}{|c|}{$\begin{array}{l}\text { Experimental } \\
\text { conditions }\end{array}$} & \multirow[t]{2}{*}{$\mathrm{q}_{\mathrm{m}}\left(\mathrm{mg} \mathrm{g}^{-1}\right)$} & \multirow[t]{2}{*}{ Ref } \\
\hline & $\mathrm{T}(\mathrm{K})$ & $\mathrm{pH}$ & & \\
\hline$\beta-\mathrm{CD}$ polymer crosslinked by citric acid (P1) & 303 & $\overline{\text { n.a }}$ & 9.69 & (Zhao et al., 2009) \\
\hline $\mathrm{PMMA} / \mathrm{SiO}_{2}$ & 273 & 8 & 140 & (An et al., 2010) \\
\hline Calix[6]-1,4-crown-based polymer & 298 & $6-10$ & 214.2 & (Guo et al., 2012) \\
\hline $\begin{array}{l}\text { Hyper-cross-linked resin modified with phenolic hydroxyl } \\
\text { group (GQ03) }\end{array}$ & 293 & n.a & 188.3 & (Xiao and Long, 2012) \\
\hline Sawdust- $\beta-C D$ polymers & 288 & 7 & 84 & (Hu et al., 2014) \\
\hline Molecularly imprinted polymers (MIPs) & 298 & 7 & 0.76 & (Huang et al., 2014) \\
\hline Phenol-modified hyper-cross-linked resins (HCP-P-5\%) & 298 & n.a & 169.2 & (Kuang et al., 2017) \\
\hline Azo-linked porous organic polymers (AZO-POP-1) & 293 & n.a & 1059 & (Zhou et al., 2018) \\
\hline Electrospun PIM-1 fiber & 293 & 6 & 161.2 & (Satilmis and Uyar, 2018) \\
\hline ST-DVB-WH57 & 303 & n.a & 327.5 & (Yu et al., 2018) \\
\hline $\begin{array}{l}\text { Porous hyper-cross-linked polymers modified with phenolic } \\
\text { hydroxyl groups (PHBA-HCLP) }\end{array}$ & 298 & n.a & 184.8 & (Wang et al., 2018) \\
\hline Polydivinylbenzene cryogels & 298 & n.a & 333.3 & (Guo et al., 2019) \\
\hline PS-PH-HCP & 303 & n.a & 178.8 & (Gan et al., 2019) \\
\hline Anisole-modified hyper-cross-linked resin (PS-AI-HCLR) & & & 200.6 & (Zeng and Huang, 2020) \\
\hline PIM-2 powder & 298 & 6 & 82.4 & This work \\
\hline
\end{tabular}




\section{CONCLUSIONS}

PIM-2 was assessed as a potential adsorbent for aniline removal from water. Adsorption isotherm and kinetic models were analysed by non-linear regression analysis method. Additionally, obtained data were compared using several error analysis methods to determine the best model. Liu isotherm offers the highest accuracy for predicting the adsorption of aniline onto PIM-2. The equilibrium adsorption capacity $\left(q_{\mathrm{m}}\right)$ was determined as $82.4 \mathrm{mg} \mathrm{g}^{-1}$ at $\mathrm{pH} 6$ and $298 \mathrm{~K}$. The kinetic process can be predicted by the pseudo second-order kinetic model. Calculated thermodynamic parameters suggested spontaneous and exothermic process and adsorption is more favorable at low temperature.

\section{REFERENCES}

Ahmadi M, Mohammadian M, Khosravi-Nikou MR, Baghban A, 2019. Experimental, Kinetic, and Thermodynamic Studies of Adsorptive Desulfurization and Denitrogenation of Model Fuels Using Novel Mesoporous Materials. Journal of Hazardous Materials, 374: 129-139.

An F, Feng X, Gao B, 2010. Adsorption Property and Mechanism of Composite Adsorbent PMMA/SiO2 for Aniline. Journal of Hazardous Materials, 178 (1): 499-504.

Budd PM, Ghanem BS, Makhseed S, McKeown NB, Msayib KJ, Tattershall CE, 2004. Polymers of Intrinsic Microporosity (PIMs): Robust, Solution-Processable, Organic Nanoporous Materials. Chemical Communications, (2): 230-231.

Budd PM, McKeown NB, Fritsch D, 2005. Free Volume and Intrinsic Microporosity in Polymers. Journal of Materials Chemistry, 15 (20): 1977-1986.

Budd PM, McKeown NB, Ghanem BS, Msayib KJ, Fritsch D, Starannikova L, Belov N, Sanfirova O, Yampolskii Y, Shantarovich V, 2008. Gas Permeation Parameters and Other Physicochemical Properties of a Polymer of Intrinsic Microporosity: Polybenzodioxane PIM-1. Journal of Membrane Science, 325 (2): 851-860.

Foo KY, Hameed BH, 2010. Insights into the Modeling of Adsorption Isotherm Systems. Chemical Engineering Journal, 156 (1): 2-10.

Freundlich H, 1906. Over the Adsorption in Solution. Journal of Physical Chemistry, 57: 385-471.

Fuoco A, Satilmis B, Uyar T, Monteleone M, Esposito E, Muzzi C, Tocci E, Longo M, De Santo MP, Lanč M, Friess K, Vopička O, Izák P, Jansen JC, 2020. Comparison of Pure and Mixed Gas Permeation of the Highly Fluorinated Polymer of Intrinsic Microporosity PIM-2 under Dry and Humid Conditions: Experiment and Modelling. Journal of Membrane Science, 594: 117460.

Gan Y, Chen G, Sang Y, Zhou F, Man R, Huang J, 2019. Oxygen-Rich Hyper-Cross-Linked Polymers with Hierarchical Porosity for Aniline Adsorption. Chemical Engineering Journal, 368: 29-36.

Gao D-W, Hu Q, Pan H, Jiang J, Wang P, 2015. High-Capacity Adsorption of Aniline Using Surface Modification of Lignocellulose-Biomass Jute Fibers. Bioresource Technology, 193: 507-512.

Gheewala SH, Annachhatre AP, 1997. Biodegradation of Aniline. Water Science and Technology, 36 (10): 5363.

Ghosal PS, Gupta AK, 2017. Determination of Thermodynamic Parameters from Langmuir Isotherm ConstantRevisited. Journal of Molecular Liquids, 225: 137-146.

Günay A, Arslankaya E, Tosun İ, 2007. Lead Removal from Aqueous Solution by Natural and Pretreated Clinoptilolite: Adsorption Equilibrium and Kinetics. Journal of Hazardous Materials, 146 (1): 362-371.

Guo F, Wang Y, Chen X, Chen M, He W, Chen Z, 2019. Supermacroporous Polydivinylbenzene Cryogels with High Surface Area: Synthesis by Solvothermal Postcrosslinking and Their Adsorption Behaviors for Carbon Dioxide and Aniline. Journal of Applied Polymer Science, 136 (27): 47716.

Guo H, Yang F, Chai X, Jiao Z, Li C, 2012. Synthesis of Novel Calix[6]-1,4-Crown-Based Netty Polymer and Its Excellent Adsorption Capabilities for Aniline Derivatives. Iranian Polymer Journal, 21 (7): 451-456.

Harrache Z, Abbas M, Aksil T, Trari M, 2019. Thermodynamic and Kinetics Studies on Adsorption of Indigo Carmine from Aqueous Solution by Activated Carbon. Microchemical Journal, 144: 180-189. 
Ho YS, McKay G, 1999. Pseudo-Second Order Model for Sorption Processes. Process Biochemistry, 34 (5): 451465.

Hu Q, Gao D-W, Pan H, Hao L, Wang P, 2014. Equilibrium and Kinetics of Aniline Adsorption onto Crosslinked Sawdust-Cyclodextrin Polymers. Rsc Advances, 4 (75): 40071-40077.

Huang Y, Xu Y, He Q, Cao Y, Du B, 2014. Rapid Removal of Aniline from Contaminated Water by a Novel Polymeric Adsorbent. Water Environment Research, 86 (1): 20-27.

Igberase E, Ofomaja A, Osifo PO, 2019. Enhanced Heavy Metal Ions Adsorption by 4-Aminobenzoic Acid Grafted on Chitosan/Epichlorohydrin Composite: Kinetics, Isotherms, Thermodynamics and Desorption Studies. International Journal of Biological Macromolecules, 123: 664-676.

Khan EA, Shahjahan, Khan TA, 2018. Adsorption of Methyl Red on Activated Carbon Derived from Custard Apple (Annona Squamosa) Fruit Shell: Equilibrium Isotherm and Kinetic Studies. Journal of Molecular Liquids, 249: 1195-1211.

Kuang W, Liu Y-N, Huang J, 2017. Phenol-Modified Hyper-Cross-Linked Resins with Almost All Micro/Mesopores and Their Adsorption to Aniline. Journal of Colloid and Interface Science, 487: 31-37.

Lagergren S, 1898. About the Theory of So Called Adsorption of Soluble Substances. Kungliga Svenska Vetenskapsakademiens Handlingar, 24 (4): 1-39.

Langmuir I, 1916. The Constitution and Fundamental Properties of Solids and Liquids. Part I. Solids. Journal of the American Chemical Society, 38 (11): 2221-2295.

Lima ÉC, Adebayo MA, Machado FM, 2015. Carbon Nanomaterials as Adsorbents for Environmental and Biological Applications.Carbon Nanostructures. Springer, pp. 33-71, Brazil.

Lima EC, Hosseini-Bandegharaei A, Moreno-Piraján JC, Anastopoulos I, 2019. A Critical Review of the Estimation of the Thermodynamic Parameters on Adsorption Equilibria. Wrong Use of Equilibrium Constant in the Van't Hoof Equation for Calculation of Thermodynamic Parameters of Adsorption. Journal of Molecular Liquids, 273: 425-434.

Liu Y, Liu X, Dong W, Zhang L, Kong Q, Wang W, 2017. Efficient Adsorption of Sulfamethazine onto Modified Activated Carbon: A Plausible Adsorption Mechanism. Scientific Reports, 7 (1): 12437.

Liu Y, Xu H, Yang S-F, Tay J-H, 2003. A General Model for Biosorption of Cd2+, Cu2+ and Zn2+ by Aerobic Granules. Journal of Biotechnology, 102 (3): 233-239.

McKeown NB, Budd PM, 2006. Polymers of Intrinsic Microporosity (PIMs): Organic Materials for Membrane Separations, Heterogeneous Catalysis and Hydrogen Storage. Chemical Society Reviews, 35 (8): 675-683.

McKeown NB, Budd PM, Msayib KJ, Ghanem BS, Kingston HJ, Tattershall CE, Makhseed S, Reynolds KJ, Fritsch D, 2005. Polymers of Intrinsic Microporosity (PIMs): Bridging the Void between Microporous and Polymeric Materials. Chemistry-a European Journal, 11 (9): 2610-2620.

McLintock IS, 1967. The Elovich Equation in Chemisorption Kinetics. Nature, 216 (5121): 1204-1205.

Midda MO, Srivastava VC, Kushwaha JP, 2018. Modelling Single and Binary Adsorptive Behaviour of Aniline and Nitrobenzene onto Granular Activated Carbon. Physics and Chemistry of Liquids, 58 (2): 150-163.

Rahdar A, Rahdar S, Labuto G, 2020. Environmentally Friendly Synthesis of Fe2o3@Sio2 Nanocomposite: Characterization and Application as an Adsorbent to Aniline Removal from Aqueous Solution. Environmental Science and Pollution Research, 27 (9): 9181-9191.

Satilmis B, 2020. Amidoxime Modified Polymers of Intrinsic Microporosity (PIM-1); a Versatile Adsorbent for Efficient Removal of Charged Dyes; Equilibrium, Kinetic and Thermodynamic Studies. Journal of Polymers and the Environment, 28 (3): 995-1009.

Satilmis B, Uyar T, 2018. Removal of Aniline from Air and Water by Polymers of Intrinsic Microporosity (PIM1) Electrospun Ultrafine Fibers. Journal of Colloid and Interface Science, 516: 317-324.

Satilmis B, Uyar T, 2019. Development of Superhydrophobic Electrospun Fibrous Membrane of Polymers of Intrinsic Microporosity (PIM-2). European Polymer Journal, 112: 87-94. 
Sato H, Nakajo S, Oishi Y, Shibasaki Y, 2018. Synthesis of Linear Polymer of Intrinsic Microporosity from 5,5',6,6'-Tetrahydroxy-3,3,3',3'-Tetramethylspirobisindane and Decafluorobiphenyl. Reactive \& Functional Polymers, 125: 70-76.

Sriprom P, Assawasaengrat P, Neramittagapong A, Neramittagapong S, 2014. Catalytic Wet-Air Oxidation of Aniline Removal from Synthetic Wastewater. Advanced Materials Research, 931-932: 32-36.

Wang X, Mao X, Huang J, 2018. Hierarchical Porous Hyper-Cross-Linked Polymers Modified with Phenolic Hydroxyl Groups and Their Efficient Adsorption of Aniline from Aqueous Solution. Colloids and Surfaces A: Physicochemical and Engineering Aspects, 558: 80-87.

Xiao G, Long L, 2012. Efficient Removal of Aniline by a Water-Compatible Microporous and Mesoporous Hyper-Cross-Linked Resin and Xad-4 Resin: A Comparative Study. Applied Surface Science, 258 (17): 6465-6471.

Yi Z, Huajie L, Mingchun L, Meihua X, 2020. Adsorption of Aniline on Aminated Chitosan/Graphene Oxide Composite Material. Journal of Molecular Structure, 1209: 127973.

Yu W, Xu C, Yin C, Yu S, Sun W, Xie C, Xian M, 2018. Mechanism of Aniline Adsorption on Post-Crosslinked Resins: Pore Structure and Oxygen Content. Water Science and Technology, 78 (10): 2096-2103.

Zeng X, Huang J, 2020. Anisole-Modified Hyper-Cross-Linked Resins for Efficient Adsorption of Aniline from Aqueous Solution. Journal of Colloid and Interface Science, 569: 177-183.

Zhao D, Zhao L, Zhu C-S, Shen X, Zhang X, Sha B, 2009. Comparative Study of Polymer Containing BCyclodextrin and-Cooh for Adsorption toward Aniline, 1-Naphthylamine and Methylene Blue. Journal of Hazardous Materials, 171 (1): 241-246.

Zhou J-X, Luo X-S, Liu X, Qiao Y, Wang P, Mecerreyes D, Bogliotti N, Chen S-L, Huang M-H, 2018. AzoLinked Porous Organic Polymers: Robust and Time-Efficient Synthesis Via Nabh4-Mediated Reductive Homocoupling on Polynitro Monomers and Adsorption Capacity Towards Aniline in Water. Journal of Materials Chemistry A, 6 (14): 5608-5612. 